\title{
La oferta electoral del Bloque Nacionalista Galego (BNG) en las elecciones autonómicas
}

\section{The electoral offer of the Bloque Nacionalista Galego (BNG) at the regional level}

Cristina Ares Castro-Conde

Universidad de Santiago de Compostela cristina.ares@usc.es

\begin{abstract}
RESUMEN
Este trabajo analiza la oferta electoral del frente de partidos Bloque Nacionalista Galego (BNG) en las elecciones al Parlamento de Galicia desde la década de 1980. Se examinan los cambios en su estrategia electoral. En particular, los efectos de sus reposicionamientos tanto en la dimensión izquierda-derecha como en el eje centro-periferia sobre el tamaño de su representación parlamentaria y sus opciones de gobierno. Asimismo, se muestra cómo la distancia entre las preferencias políticas del BNG y de los votantes gallegos crece desde 2005.
\end{abstract}

\section{Palabras clave}

BNG, elecciones autonómicas, Galicia, Regional Manifestos Project.

\begin{abstract}
This piece of research analyses the electoral offer of the Bloque Nacionalista Galego (BNG) at the regional level since 1982. Changes in its electoral strategy are examined. Particularly, it assesses the effects of movements along both the left-right and the centre-periphery dimensions on the size of its political group as well as on its options to hold office. Light is also shed on the increasing distance between the BNG's political preferences and the voters' positions.
\end{abstract}

\section{Keywords}

BNG, regional elections, Galicia, Regional Manifestos Project.

\section{SUMARIO}

1. INTRODUCCIÓN. 2. LENGUA E IDENTIFICACIÓN TERRITORIAL EN GALICIA. 3. RESULTADOS DE LAS ELECCIONES AL PARLAMENTO DE GALICIA Y EFECTOS ORGANIZATIVOS EN EL BNG. 4. CAMBIOS EN LAS ESTRATEGIAS DE COMPETICIÓN DEL BNG. 5. LA NUEVA BRECHA ENTRE LAS PREFERENCIAS DEL BNG Y DE LOS ELECTORES. 6. CONCLUSIONES. 7. BIBLIOGRAFÍA. 


\section{INTRODUCCIÓN}

Tras las elecciones autonómicas gallegas de septiembre de 2016, en las que el Partido Popular de Galicia (PPdeG) consiguió su séptima mayoría absoluta en esta Comunidad y el Bloque Nacionalista Galego (BNG) perdió nuevamente representación parlamentaria, resulta de interés plantear la siguiente pregunta: por qué, a diferencia de otras Comunidades históricas con lengua propia, ningún partido nacionalista ha presidido la Xunta de Galicia y en solo dos ocasiones fuerzas nacionalistas, Coalición Galega (CG) y el Partido Nacionalista Galego (PNG) [tras una moción de censura en septiembre de 1987 - hasta febrero de 1990] y el Bloque Nacionalista Galego (BNG) [2005-2009], han formado parte de un Ejecutivo de coalición liderado por la rama autonómica del Partido Socialista (PSdeG-PSOE).

Para dar respuesta a esta cuestión, este trabajo examina la estrategia de competición del BNG, frente nacionalista que, junto a los partidos de ámbito estatal PPdeG y PSdeG-PSOE, ha conseguido representación parlamentaria ininterrumpidamente en esta Asamblea desde los primeros comicios de 1981. Se observan además las preferencias del electorado gallego acerca de los niveles de autogobierno, que desde 2005 se han vuelto más centralistas. El estudio se completa con referencias a las estrategias del PPdeG y del PSdeG-PSOE. El primero mantuvo una posición properiférica moderada, desviándose en este eje de competición de la posición del PP en el ámbito estatal así como en el de las Comunidades Autónomas de Cataluña y el País Vasco. El segundo, tras ser superado en votos y escaños por el BNG, en 1997, decidió prestar también más atención a la dimensión centro-periferia en su estrategia electoral a nivel autonómico.

El método es el análisis de contenido de textos políticos del Regional Manifestos Project (Alonso, VoIkens, Gómez, 2012; Alonso, Gómez y Cabeza, 2013). Se emplean los programas electorales de AP, el PSdeG-PSOE y el BNPG de 1981; y los programas del PPdeG, el PSdeG-PSOE y el BNG de 1993, 2001, 2009 y $2012^{1}$. La información acerca de las preferencias de los electores procede de los Barómetros autonómicos del Centro de Investigaciones Sociológicas (CIS) para Galicia I, II y III, correspondientes a los años 2005, 2010 y 2012, únicos disponibles. También, se hace uso de estudios sociodemográficos del Instituto Galego de Estatística (IGE, Instituto Gallego de Estadística).

En cuanto a la estructura del texto, para comenzar, se repasa la situación de la lengua propia y los datos de identificación territorial de Galicia. A continuación, se resumen los resultados de las elecciones al Parlamento gallego y algunos de sus efectos organizativos sobre el BNG. Posteriormente, se abordan, en primer lugar, los cambios en las estrategias de competición del BNG y su conexión con las estrategias de las otras dos fuerzas políticas con representación en la Asamblea autonómica desde 1981 (PPdeG y PSdeG-PSOE); y, en segundo lugar, la transformación desde 2005 de las preferencias de los votantes gallegos sobre el modelo territorial. Éste ha coadyuvado al crecimiento de la brecha entre las posiciones en el eje centro-periferia del BNG y del electorado.

\section{LENGUA E IDENTIFICACIÓN TERRITORIAL EN GALICIA}

Lengua. Incluso para los habitantes de Galicia que no hablan gallego, la lengua propia es uno de los elementos definitorios de la identidad regional. Además, como se refleja en el gráfico 1, el $31,2 \%$ de la población habla siempre en gallego, y solo el $13,07 \%$ tiene poca o ninguna capacidad para emplearlo.

Identificación territorial. Persiste en Galicia un característico «sentimiento difuso de pueblo diferenciado» (Máiz, 1996: 69). En esta Comunidad, apenas se encuentran ciudadanos que se identifiquen en exclusiva con el Estado o con la región. En 2012, quienes se sentían únicamente españoles o solo gallegos sumaban en ambos casos menos del 3\% (CIS). En cambio, el 69,9\% se sentían tan españoles como gallegos, y el $21,7 \%$ más gallegos que españoles. En 2012, en una escala de 0 (mínimo nacionalismo gallego) a 10 (máximo nacionalismo gallego), el 44\% de la población se ubicaba en las posiciones 4-6 (CIS). Sin embargo, el 48\% estaban bastante o muy en contra de llamar a Galicia «nación».

En las elecciones autonómicas de 1981 se presentó Alianza Popular en lugar del Partido Popular, y el Bloque Nacional Popular Galego (BNPG) en vez del BNG. El BNPG integraba la Unión do Pobo Galego (UPG), organización que conforma el núcleo duro del BNG, y la Asamblea Popular Galega. El BNG fue creado en 1982. 
REALA. Nueva Época - N. 6, noviembre 2016 - ISSN: 1989-8975 - DOI: 10.24965/reala.v0i6.10387 - [Págs. 55-69]

La oferta electoral del Bloque Nacionalista Galego (BNG) en elecciones autonómicas

Gráfico 1. Lengua hablada en Galicia

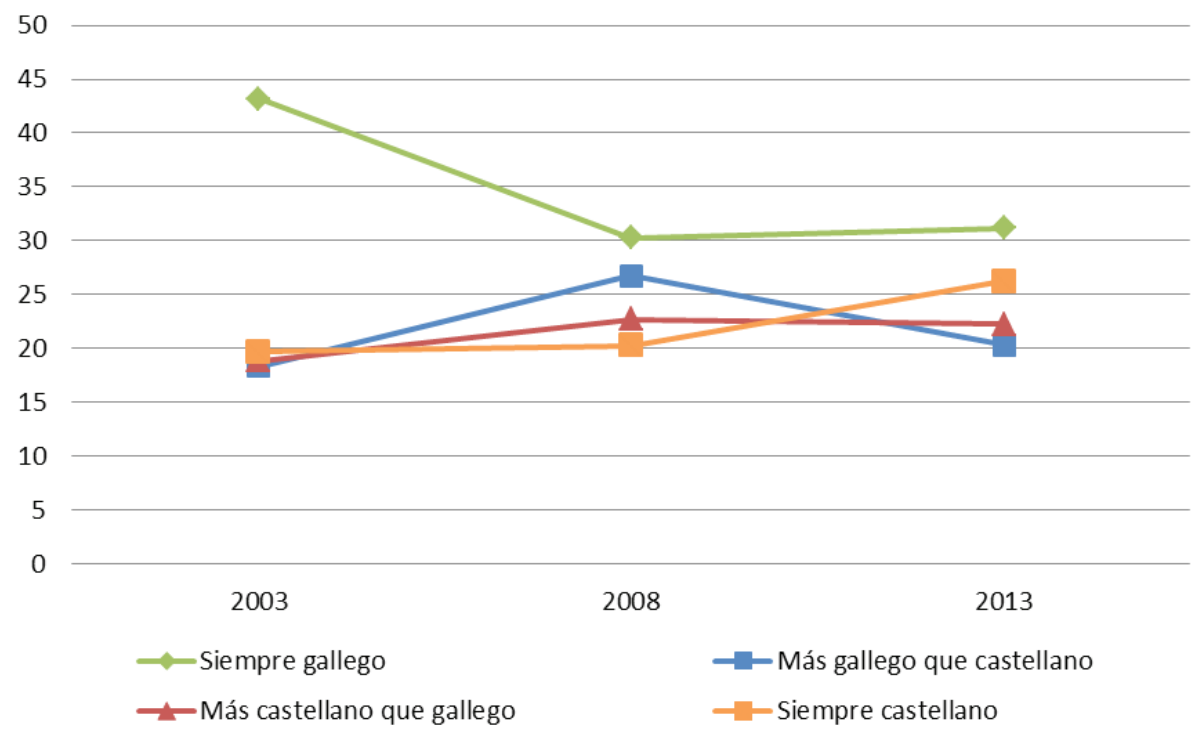

Fuente: IGE, Encuesta de condiciones de vida de las familias. Conocimiento y uso del gallego

Gráfico 2. Identificación territorial de los gallegos

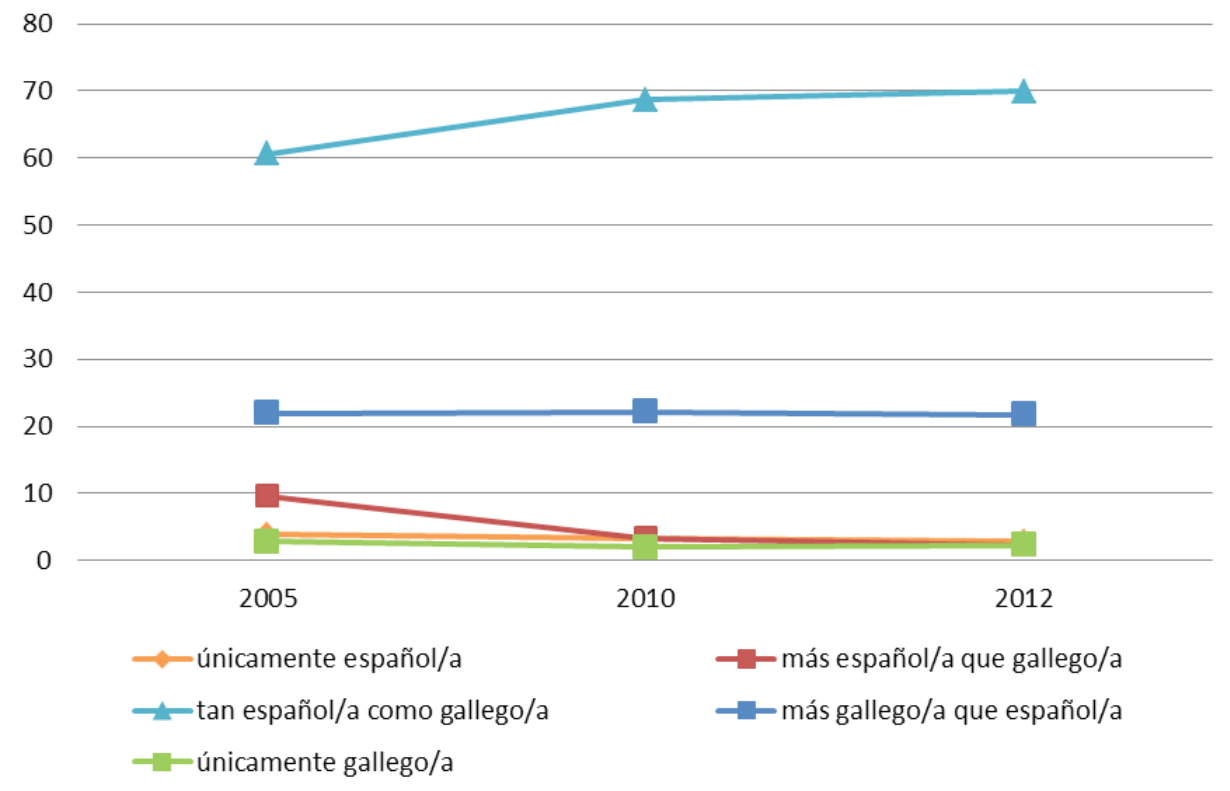

Fuente: CIS, Barómetros autonómicos I, II y III

\section{RESULTADOS DE LAS ELECCIONES AL PARLAMENTO DE GALICIA Y EFECTOS ORGANIZATIVOS EN EL BNG}

Resultados electorales. En las primeras elecciones autonómicas celebradas en 1981 obtuvieron asientos en el Parlamento de Galicia seis partidos o coaliciones: AP, UCD, PSdeG-PSOE, BNPG-PSG, EG y PCG-EU. En 1985 y 1989, lograron representación cinco: PPdeG, PSdeG-PSOE, BNG, CG y EG$\mathrm{PSG}^{2}$. En 1992, la barrera legal se elevó del 3\% al 5\% en cada provincia. Este cambio redujo, a partir de

2 Para conocer la evolución de los partidos nacionalistas en Galicia, véase Máiz (2001). 
REALA. Nueva Época - N. 6, noviembre 2016 - ISSN: 1989-8975 - DOI: 10.24965/reala.v0i6.10387 - [Págs. 55-69]

La oferta electoral del Bloque Nacionalista Galego (BNG) en elecciones autonómicas

Cristina Ares Castro-Conde

los comicios de 1993, la fragmentación y el número de partidos. En 1993, Coalición Galega, que había obtenido 11 escaños en 1985 (12,94\% de votos) y 2 en 1989 (3,64\%), perdió su condición de fuerza parlamentaria, convirtiendo al PPdeG en el único partido a la derecha del PSdeG-PSOE. De 1993 a 2012, solo obtuvieron representación PPdeG, PSdeG-PSOE y BNG.

Tabla I. Resultados de las elecciones al Parlamento de Galicia (1981-2016). Número de escaños

\begin{tabular}{|c|c|c|c|c|c|c|c|c|c|c|}
\hline Candidatura & 1981 & 1985 & 1989 & 1993 & 1997 & 2001 & 2005 & 2009 & 2012 & 2016 \\
\hline AP/PPdeG & 26 & 34 & 38 & 43 & 42 & 41 & 37 & 38 & 41 & 41 \\
\hline UCD & 24 & & & & & & & & & \\
\hline PSdeG-PSOE & 16 & 22 & 28 & 19 & 15 & 17 & 25 & 25 & 18 & 14 \\
\hline BNPG/BNG & 3 & 1 & 5 & 13 & 18 & 17 & 13 & 12 & 7 & 6 \\
\hline AGE/En Marea & & & & & & & & & 9 & 14 \\
\hline CG & & 11 & 2 & & & & & & & \\
\hline$E G$ & 1 & 3 & 2 & & & & & & & \\
\hline PCG-EU & 1 & & & & & & & & & \\
\hline Total escaños & 71 & 71 & 75 & 75 & 75 & 75 & 75 & 75 & 75 & 75 \\
\hline
\end{tabular}

Fuente: elaboración propia

En 2012, la coalición electoral Alternativa Galega de Esquerdas (AGE), conformada por Esquerda Unida (EU) y la fuerza nacionalista Anova, escindida del BNG y liderada por su histórico portavoz parlamentario, Beiras Torrado, consiguió, en cambio, irrumpir en el Parlamento con 9 escaños, y desplazar de tercera a cuarta fuerza al BNG, que solo logró 7 asientos. En las elecciones de septiembre de 2016, En Marea (Anova, EU, Podemos y otros) logró, como el PSdeG-PSOE, 14 diputados, y el BNG perdió 1, quedándose en 6.

Gráfico 3. Resultados de las elecciones al Parlamento de Galicia (1981-2016). Porcentaje de voto

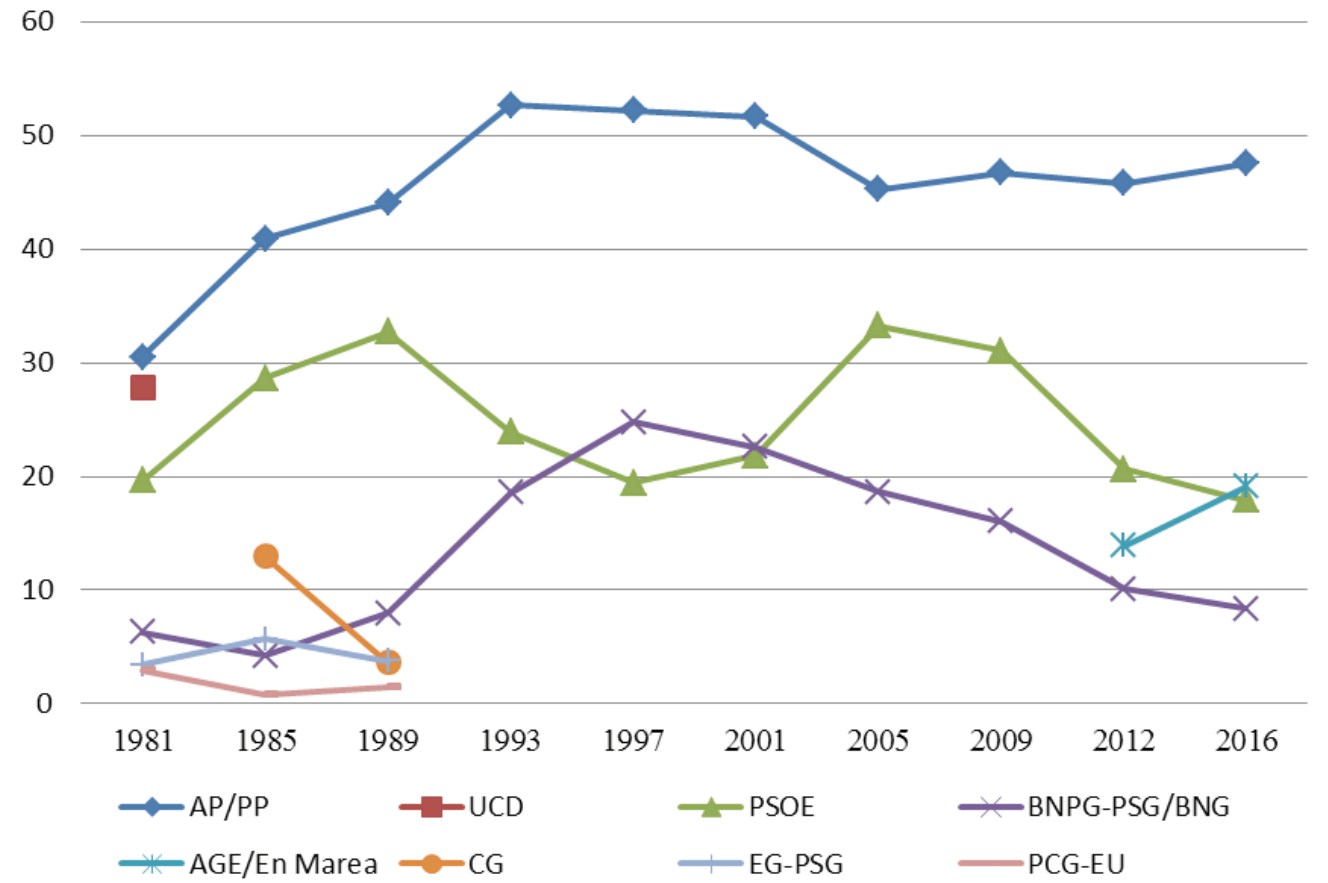

Fuente: elaboración propia 
REALA. Nueva Época - N. 6, noviembre 2016 - ISSN: 1989-8975 - DOI: 10.24965/reala.v0i6.10387 - [Págs. 55-69]

La oferta electoral del Bloque Nacionalista Galego (BNG) en elecciones autonómicas

Cristina Ares Castro-Conde

En lo relativo a la composición del Ejecutivo, el PPdeG ha sido el partido de gobierno en Galicia desde 1981, con la única excepción del bipartido entre PSdeG-PSOE y BNG (2005-2009), y el período anterior a las elecciones de 1989 y posterior al reemplazo a través de una moción de censura en 1987 del primer presidente popular, Fernández Albor, por el socialista, González Laxe.

Tabla II. Presidentes de la Xunta de Galicia (1981-2016)

\begin{tabular}{lcll}
\hline & Legislatura & Presidente & Partido \\
\hline $22 / 01 / 1982$ & I y II & Gerardo Fernández Albor & AP/PPdeG \\
\hline $\begin{array}{l}\text { Moción de censura } \\
26 / 09 / 1987\end{array}$ & II & Fernando González Laxe & PSdeG-PSOE \\
& & & Gobierno tripartito (PSdeG-PSOE, CG y PNG) \\
\hline $05 / 02 / 1990$ & III a VI & Manuel Fraga Iribarne & PPdeG \\
\hline $02 / 08 / 2005$ & VII & Emilio Pérez Touriño & PSdeG-PSOE \\
& & & Gobierno bipartito (PSdeG-PSOE, BNG) \\
\hline $16 / 04 / 2009$ & VIII, IX y X & Alberto Núñez Feijoo & PPdeG \\
\hline
\end{tabular}

Fuente: elaboración propia

Efectos del fin del bipartito en el BNG. Tras la nueva mayoría absoluta del PPdeG en 2009 y el fin de los cuatro años de bipartito, dimitió la dirección del BNG, encabezada por Anxo Quintana, ex-Vicepresidente de la Xunta de Galicia. Entonces, el frente nacionalista celebró una asamblea extraordinaria, en la cual la UPG, su partido nuclear, con una lista encabezada por Guillerme Vázquez, se hizo con el control de la ejecutiva. Beiras Torrado fracasó en su intento de pilotar el BNG, tanto en ésta como en la asamblea ordinaria de enero de 2012. Tras la segunda, abandonaron el frente Encontro Irmandiño, Esquerda Nacionalista, el Partido Nacionalista Galego-Partido Galeguista, y un sector de Máis Galiza. En mayo, de la confluencia de Máis Galiza, Ecogaleguistas, Acción Galega, Partido Nacionalista Galego-Partido Galeguista y la histórica Coalición Galega, se creó la nueva fuerza Compromiso por Galicia. En julio, impulsada por el Encontro Irmandiño liderado por Beiras, se fundó también, Anova-Irmandade Nacionalista, donde se integraron Frente Popular Galega, Movemento pola Base y Nova Esquerda Galega. En 2013, una nueva asamblea del BNG fijó la independencia de Galicia como objetivo político. En las elecciones generales de diciembre de 2015, el BNG, integrado en la coalición Nós-Candidatura Galega, perdió la representación en el Congreso de los Diputados que mantenía desde 1996 (2 escaños, salvo en la legislatura 20002004, cuando contó con 3). En estos comicios, En Marea (AGE + Podemos) superó el apoyo electoral del PSdeG-PSOE en Galicia, y accedió al Congreso con 6 asientos. En la asamblea del BNG celebrada en febrero de 2016, por primera vez una militante de la UPG, Ana Pontón, asumió la dirección del frente, que decidió además no explorar la confluencia con partidos de ámbito estatal como Podemos y Esquerda Unida de cara a los comicios autonómicos de septiembre. Las últimas elecciones gallegas consolidaron a Ana Pontón también como nueva candidata nacionalista a presidir la Xunta. No obstante, el resultado supuso un nuevo retroceso para el BNG.

\section{CAMBIOS EN LAS ESTRATEGIAS DE COMPETICIÓN DEL BNG}

Desde las primeras elecciones autonómicas celebradas en Galicia en 1981, el BNG ha desplegado una estrategia bidimensional, atribuyendo una importancia similar a las dos dimensiones de competición relevantes en la sociedad gallega, que son la izquierda-derecha y la centro-periferia. La única excepción fueron los comicios de 2001, en los que el BNG confirió ligeramente más importancia de lo habitual a la dimensión ideológica. 
Gráfico 4. Ratio izquierda-derecha/centro-periferia en la oferta electoral de los partidos gallegos en elecciones autonómicas

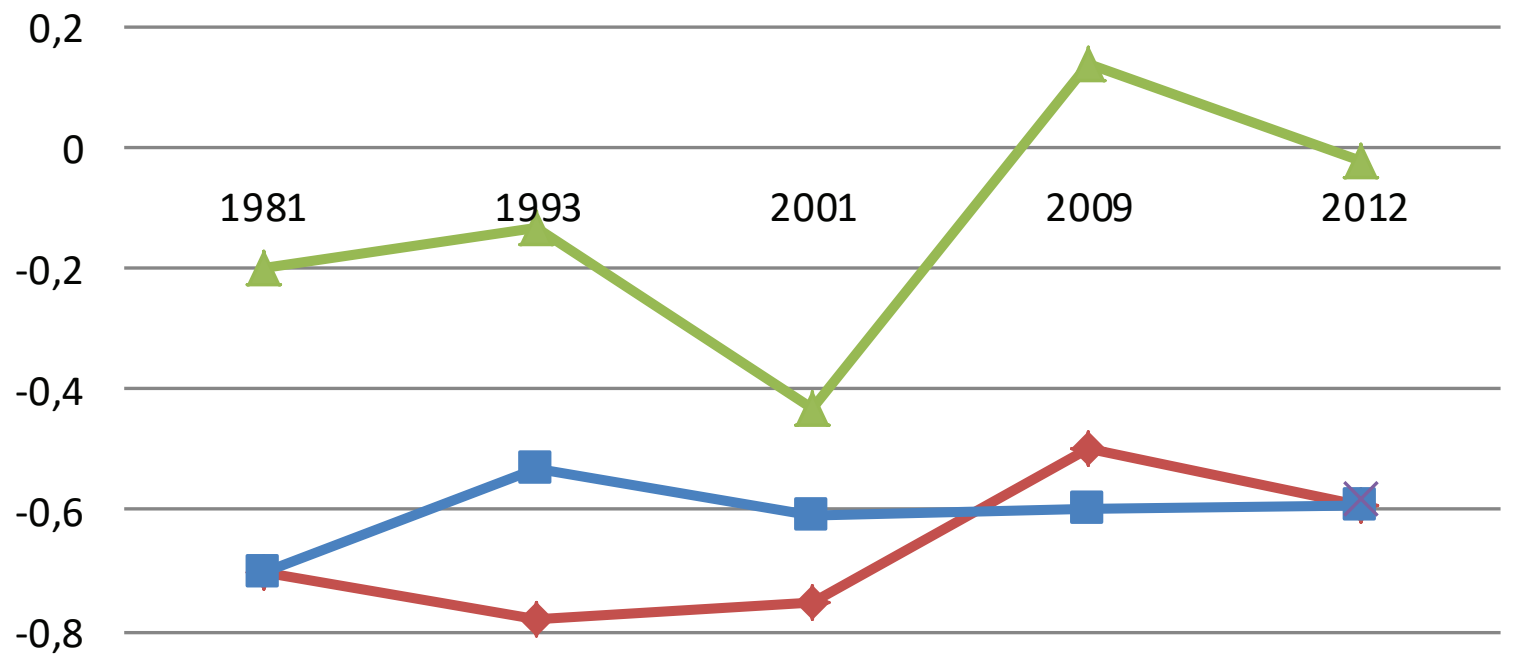

$-1$

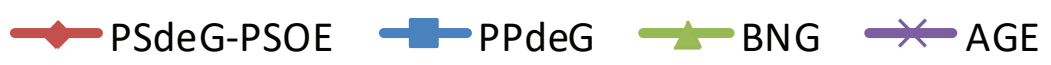

Fuente: Regional Manifestos Project ${ }^{3}$

Para el PPdeG y el PSdeG-PSOE, en cambio, siendo los dos ejes de competición relevantes, se puede hablar de una dimensión primaria, la ideológica, y una secundaria, la territorial. Las diferencias entre los dos partidos de ámbito estatal en la ratio izquierda-derecha/centro-periferia también han sido claras. El PPdeG mantiene el mismo equilibrio entre las dos dimensiones desde finales de la década de 1980, cuando el liderazgo de Fraga Iribarne facilitó la decisión de competir con claridad no solo en el eje ideológico sino también en el territorial. Mientras, la estrategia del PSdeG-PSOE ha sido más variable. Con excepción de los comicios de 1981, en los que confirió el mismo protagonismo que AP a ambos ejes, hasta finales de la década de 1990, los socialistas mantuvieron una diferencia mayor que los populares entre sus dimensiones primaria y secundaria de competición. El cambio estratégico del PSdeG-PSOE en lo relativo a la importancia del eje territorial se produjo tras las elecciones autonómicas de 1997, cuando los socialistas cayeron por vez primera por debajo del $20 \%$ de los votos $(19,46 \%)$, y fueron superados, también novedosamente, por el BNG $(24,78 \%)$. Los de 1997 fueron los comicios más exitosos en términos de apoyo electoral para el frente nacionalista. EI PSdeG-PSOE, con 15 escaños, perdió su condición de segunda fuerza parlamentaria a favor del BNG, con 18 asientos. Evidenciada de este modo la amenaza que el BNG, claro competidor en el espacio de la izquierda, suponía para el PSdeG-PSOE, éste último comenzó a prestar más atención a la dimensión territorial. De hecho, en los comicios de 2009 y 2012, los socialistas, tras gobernar en coalición con los nacionalistas, de 2005 a 2009, mantuvieron un equilibrio próximo al del PPdeG entre los dos ejes de competición. Incluso, en 2009 superaron a los populares en importancia del eje territorial sobre el ideológico.

Más allá de su carácter bidimensional, que como se acaba de apuntar ha sido una constante, la estrategia de competición del BNG entre 1981 y 2016 ha sufrido notables variaciones: ha sido agresiva desde la década de 1990 hasta 2001, etapa en la que evolucionó desde la radicalidad ideológica y territorial a la moderación, y defensiva a partir de entonces, con la recuperación de sus posiciones más extremas.

En el gráfico 5 se aprecia claramente la evolución en forma de «V» de la posición territorial del frente: moderación primero y, a partir de 2001, cambio de dirección desde una posición pro-periférica moderada de

3 El indicador oscila entre -1 (máxima importancia relativa de la dimensión izquierda-derecha) y 1 (máxima importancia relativa de la dimensión centro-periferia). El valor 0 significa igual énfasis en ambos ejes de competición. 
REALA. Nueva Época - N. 6, noviembre 2016 - ISSN: 1989-8975 - DOI: 10.24965/reala.v0i6.10387 - [Págs. 55-69]

La oferta electoral del Bloque Nacionalista Galego (BNG) en elecciones autonómicas

vuelta a la situación más extrema de los primeros comicios de $1981^{4}$. El reposicionamiento en el eje centroperiferia del BNG de 2009 a 2012 parece favorecido por la entrada de AGE. Esta coalición, impulsada por Anova (hasta entonces, partido frentista) amenazaba con romper la concentración del voto nacionalista por primera vez desde 1993.

Gráfico 5. Posición centro-periferia de los partidos gallegos en las elecciones autonómicas

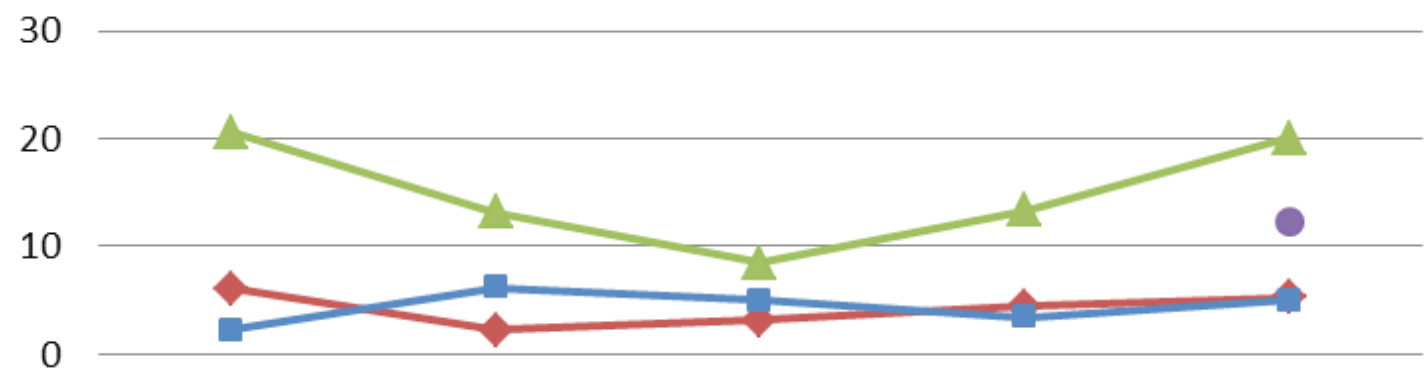

$-10$

$-20$

$-30$

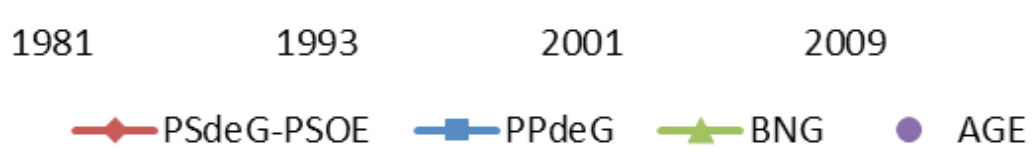

Fuente: Regional Manifestos Project ${ }^{5}$

El BNG substituyó en la década de 1990 el marco interpretativo «nacionalismo/españolismo» dominante en la UPG, núcleo duro y permanente del BNG, por otro de «proyecto común» (Fernández Baz, 2003; Gómez-Reino, 2006: 183 y 2009; Máiz, 1996: 60, y 2001: 308). Pero, desde 2001, recuperó parte del marco inicial. El programa del BNPG en 1981 diagnosticaba un problema de colonialismo interior. «El colonialismo es la causa del atraso económico y la explotación de las clases trabajadoras gallegas, así como de la negación de la realidad nacional de Galicia». La oferta electoral de 2001, en cambio, giraba en torno a «un modelo de estado de bienestar, redistribuidor, garante de condiciones laborales dignas, del acceso universalizado a los bienes inmateriales de la educación, de la sanidad, de los servicios y la seguridad social, de la cultura, del ocio, del equilibrio del ecosistema». El programa de 2012, prácticamente, de vuelta a la casilla de salida, se tituló «ipara hacerles frente gobernemos nosotros nuestra tierra!».

Así, los de 2001 fueron los comicios en los que el frente presentó una posición centro-periferia más moderada. En 2009, como ilustran los gráficos 6 y 7 , los nacionalistas aumentaron el énfasis sobre la lengua propia, solo inferior al de las primeras elecciones de 1981, así como las referencias a los lazos culturales y al compromiso con la comunidad gallega en la diáspora. En 2012, dieron más importancia, incluso que en 1981, al conjunto de los temas vinculados a la identidad gallega (gráfico 8).

\footnotetext{
4 La UPG no aceptó la Constitución Española de 1978, ni el Estatuto de Autonomía de Galicia de 1981 hasta 1982. Recordemos que en las elecciones de 1981 compite el BNPG, donde se integraba la UPG.

5 Construcción de la posición en la escala centro-periferia: periferia (22_YYY + 22_YYYY + 31_YYY + 31_YYYY + 20_301 + 20_3013 + 20_3014 + 30_301 + 20_601 + 20_6015 + 20_6016 + 20_608 + 30_602) - centro (32_YYY + 32_YYYYY + 21_YYYY + 21_YYYY + 20_302 + 30_302 + 30_601 + 30_6015 + 30_6016 + C30_608). Teóricamente oscila entre -100 (para un programa enteramente dedicado a defender una posición centralista) y +100 (para un programa exclusivamente compuesto de propuestas pro-periferia).
} 
REALA. Nueva Época - N. 6, noviembre 2016 - ISSN: 1989-8975 - DOI: 10.24965/reala.v0i6.10387 - [Págs. 55-69]

La oferta electoral del Bloque Nacionalista Galego (BNG) en elecciones autonómicas

Gráfico 6. Énfasis en la promoción y protección de la lengua propia de Galicia



Fuente: Regional Manifestos Project

Gráfico 7. Énfasis en lo lazos culturales y la ayuda gallega a su diáspora

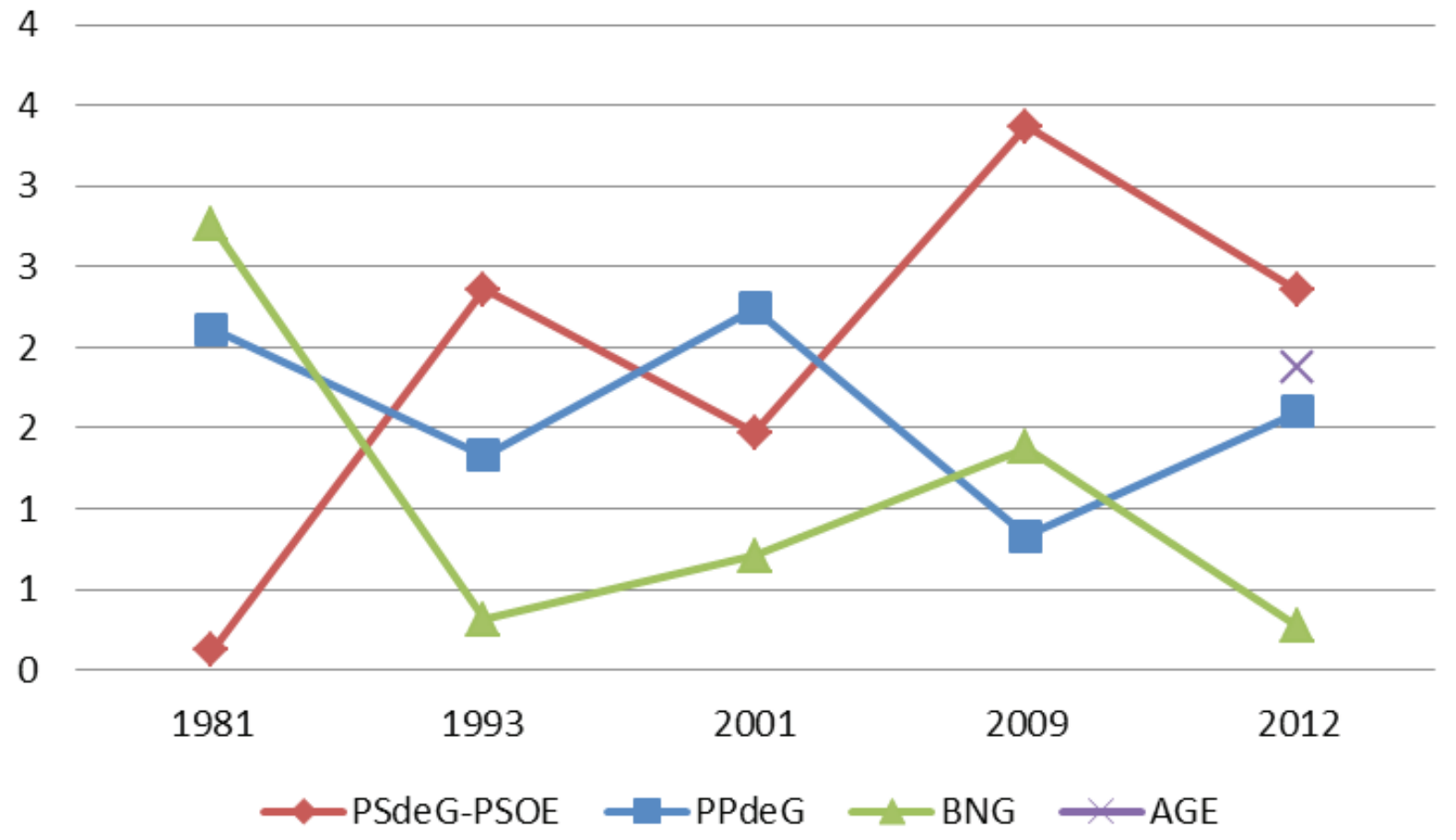

Fuente: Regional Manifestos Project 
REALA. Nueva Época - N. 6, noviembre 2016 - ISSN: 1989-8975 - DOI: 10.24965/reala.v0i6.10387 - [Págs. 55-69]

La oferta electoral del Bloque Nacionalista Galego (BNG) en elecciones autonómicas

Gráfico 8. Énfasis en la identidad gallega

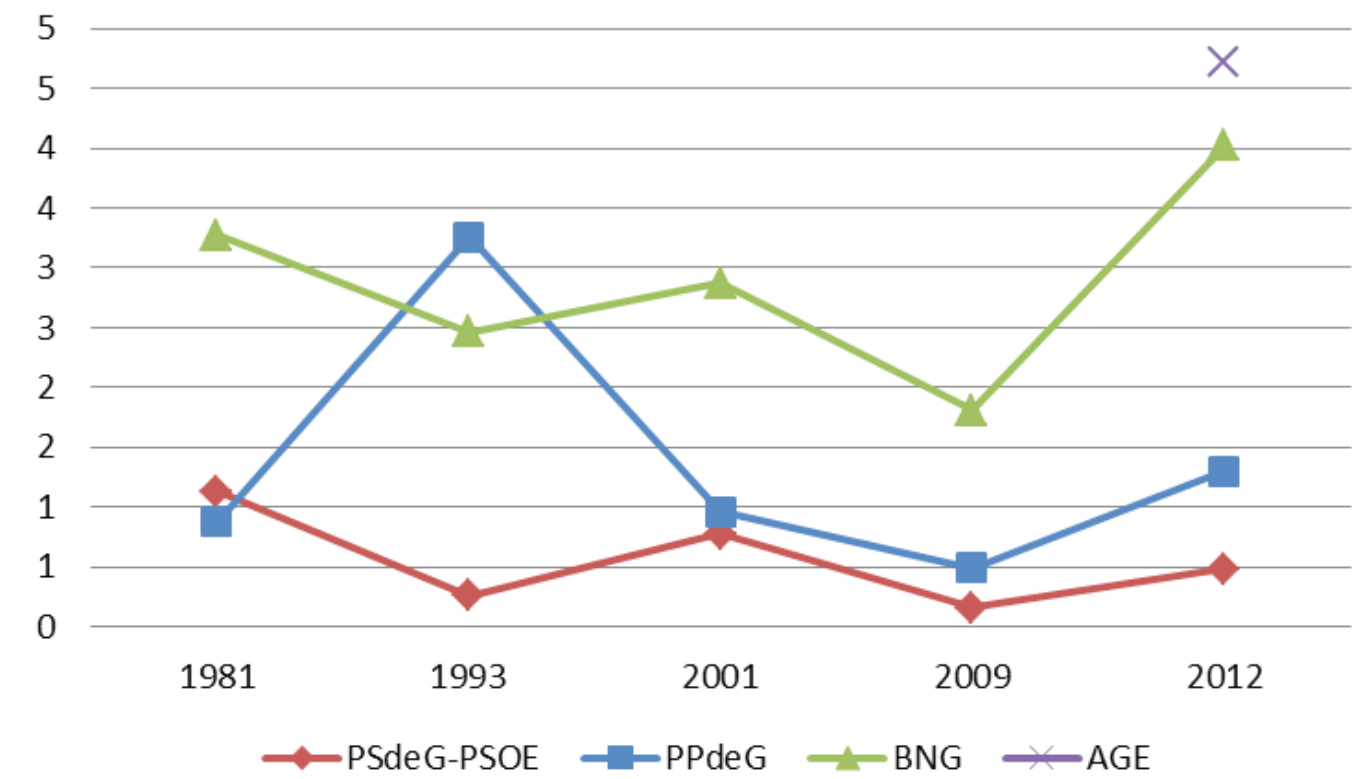

Fuente: Regional Manifestos Project

La estrategia agresiva del BNG en la década de 1990 comprendió también su moderación en el eje ideológico (Barreiro, 2003), la cual no solo duró más tiempo (la moderación en el territorial fue corregida desde 2001, como se acaba de decir), sino que se agudizó en 2009, año en el que los nacionalistas se presentaban a los comicios por primera vez desde el gobierno, conformado en 2005 en coalición con los socialistas.

Gráfico 9. Posición izquierda-derecha de los partidos gallegos en las elecciones autonómicas

$$
30
$$$$
20
$$

10

0

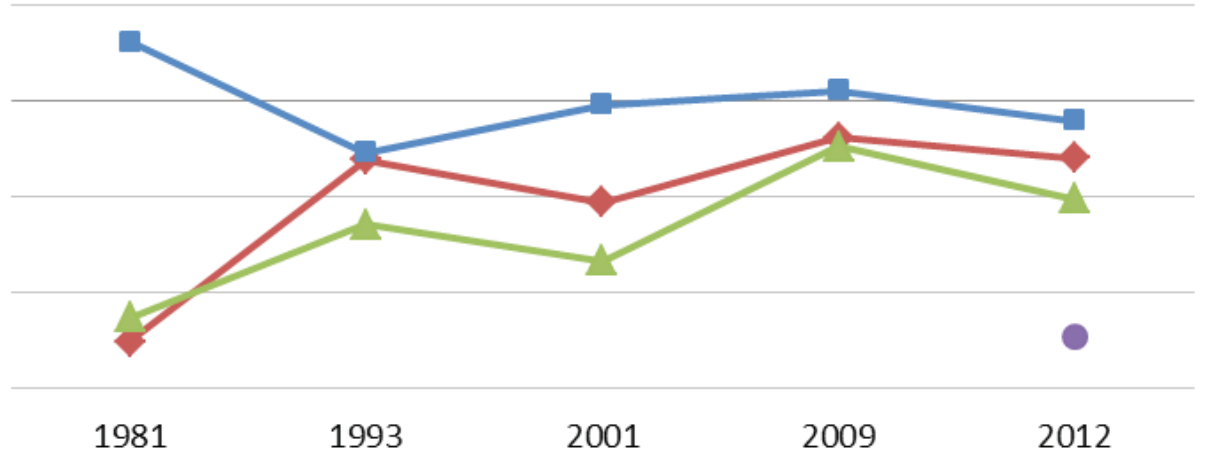

$-30$

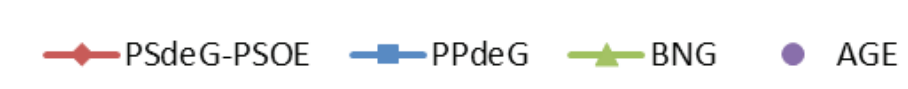

Fuente: Regional Manifestos Project ${ }^{6}$

6 Construcción de la posición en la escala izquierda-derecha: derecha $\left(X X \_104+X X \_201+30 \_203+X X \_305+X X \_401+\right.$ $X X \quad 402+X X \quad 407+X X \quad 414+X X \quad 505+X X \quad 507+X X \quad 603+X X \quad 605+X X \quad 606)$-izquierda (XX $103+X X \quad 105+\bar{X} X \quad 106+X X \quad 107$ + XX_403 + XX_404 + XX_406 + XX_412 + XX_413 + XX_701 + XX_202 + XX_2024 + XX_2025). Teóricamente oscila entre -100 (para un programa enteramente compuesto por propuestas de izquierda) y +100 (para un programa exclusivamente dedicado a ideas de derecha). 
Como se aprecia en el gráfico 9, la posición ideológica de los socios del bipartito convergió al final de su mandato en 2009, lo que implicaba un reposicionamiento ideológico espectacular del BNG, ubicado en la extrema izquierda en la década de 1980. Sin embargo, en 2012 el frente se desplazó de nuevo también en la dimensión izquierda-derecha, todavía ligeramente, pero en dirección contraria. De igual modo que en lo relativo a la dimensión centro-periferia, se entiende que este último cambio estratégico no solo obedece a la pérdida del gobierno en 2009 , sino también a la aparición de un nuevo rival claro en el espacio de la izquierda: AGE.

\section{LA NUEVA BRECHA ENTRE LAS PREFERENCIAS DEL BNG Y DE LOS ELECTORES}

Como se ha apuntado, el BNG no ha dejado de perder apoyo electoral desde los comicios de 1997, pasando del $24,78 \%$ al $8,36 \%$ obtenido en septiembre de 2016. Esta caída coincide con el abandono del marco interpretativo de proyecto común y su creciente énfasis en temas vinculados a la identidad gallega. Además, mientras el frente nacionalista no dejaba de radicalizar su posición en el eje centro-periferia, las preferencias territoriales de los electores se movían en dirección contraria, como se muestra a continuación, aumentando la brecha BNG-votantes.

En primer lugar, mientras el BNG se desplazaba hacia posiciones más extremas en la dimensión centro-periferia, menguaban los electores autoubicados más allá del 6 en la escala de nacionalismo gallego 0-10 (10 es la puntuación de máximo nacionalismo gallego). Como ilustra el gráfico 10, los votantes se han ido desplazando hacia las posiciones 4-6, que concentraban en 2012 al $44 \%$ de la población; e, incluso, en pequeña medida, hacia el extremo opuesto de mínimo nacionalismo gallego. En este gráfico, también puede apreciarse el aumento entre 2010 y 2012 de la indefinición de los electores respecto a su ubicación en la escala nacionalista. La opción de respuesta «no sabe» creció en dos años del $8 \%$ al $13,9 \%$.

\section{Gráfico 10. Ubicación de los electores en la escala de mínimo-máximo nacionalismo gallego}
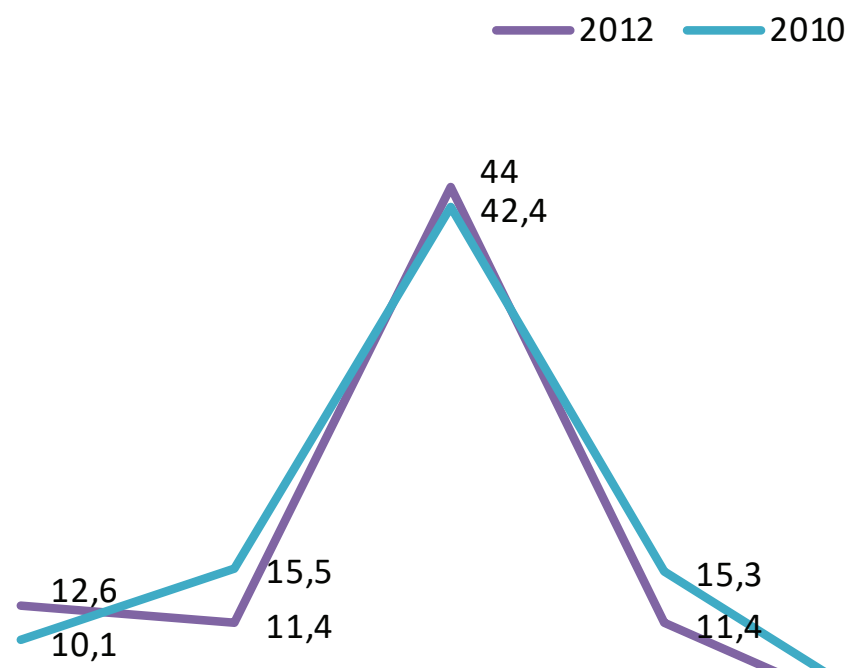

44

42,4
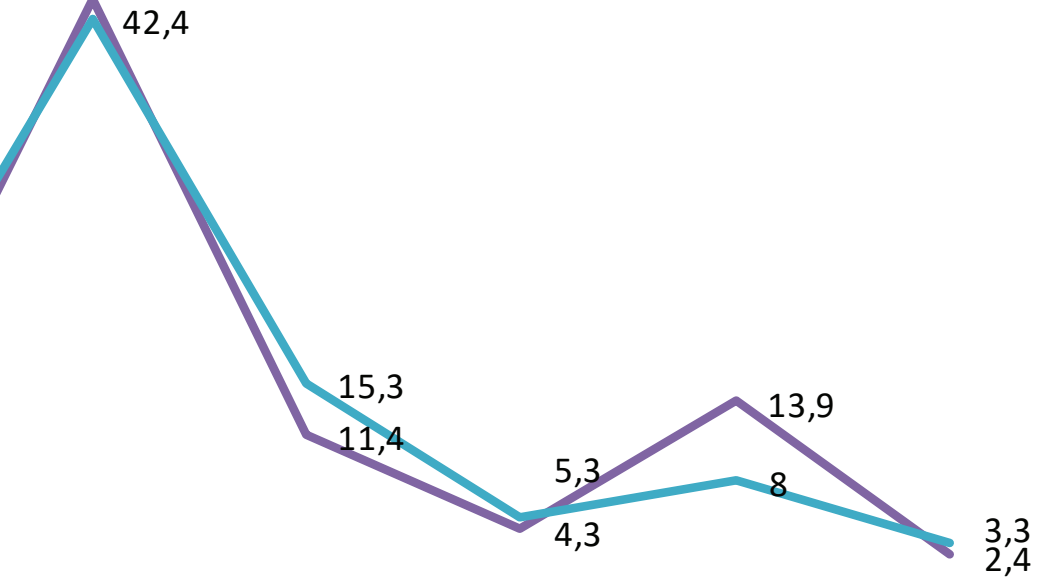

Mínimo
nacionalismo
gallego (0-1)

$(4-6)$

$(7-8)$

Máximo

N.S.

N.C.

gallego (9-10)

Fuente: CIS, Barómetros autonómicos II, y III

Entre 2005 y 2012, período para el que se dispone de datos comparables de preferencias del electorado, el apoyo a utilizar el término «nación» cayó del $17 \%$ al 11,5\%, como puede verse en el gráfico 11. 
REALA. Nueva Época - N. 6, noviembre 2016 - ISSN: 1989-8975 - DOI: 10.24965/reala.v0i6.10387 - [Págs. 55-69]

La oferta electoral del Bloque Nacionalista Galego (BNG) en elecciones autonómicas

Gráfico 11. Porcentaje de gallegos partidarios de llamar a Galicia «nación»

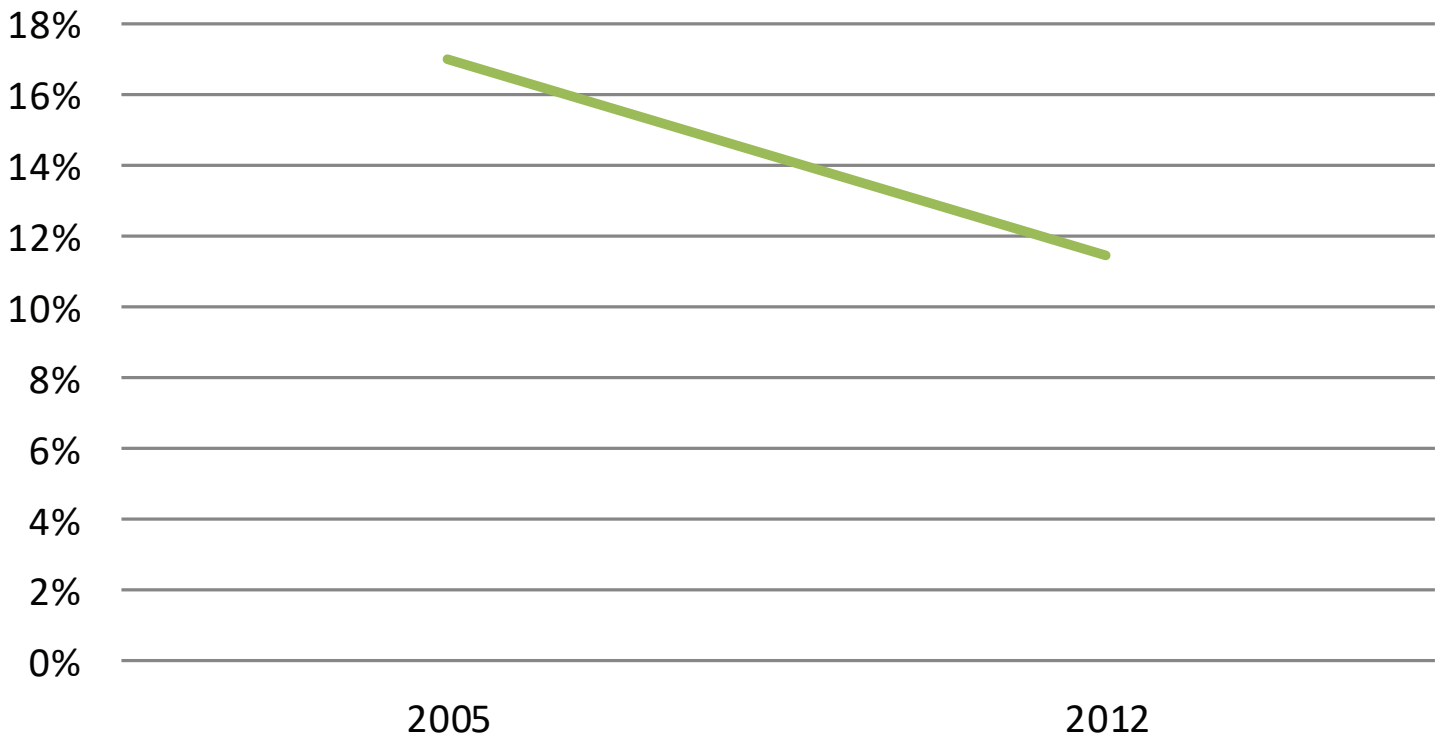

"Galicia es una nación"

Fuente: CIS, Barómetros autonómicos I, y III

Mientras que en 2005, como indica el gráfico 12, casi 7 de cada 10 gallegos valoraba positivamente el modelo territorial español, en 2012 menos de la mitad (43,6\%) apoyaban esta opción, y 3 de cada 10 se declaraban abiertamente en contra. En 2005, éstos electores representaban solo el 12,5\%.

\section{Gráfico 12. Valoración en Galicia del Estado de las Autonomías}

\section{0}

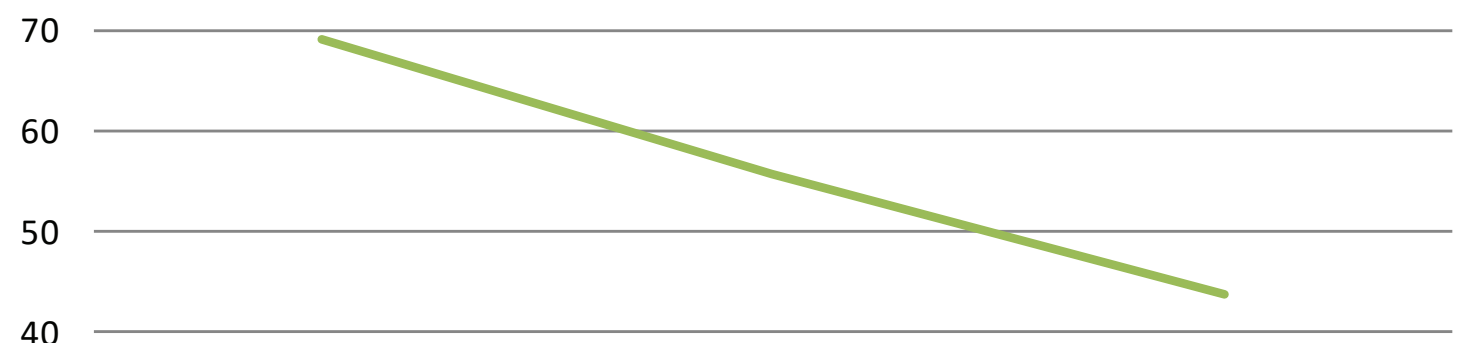

40

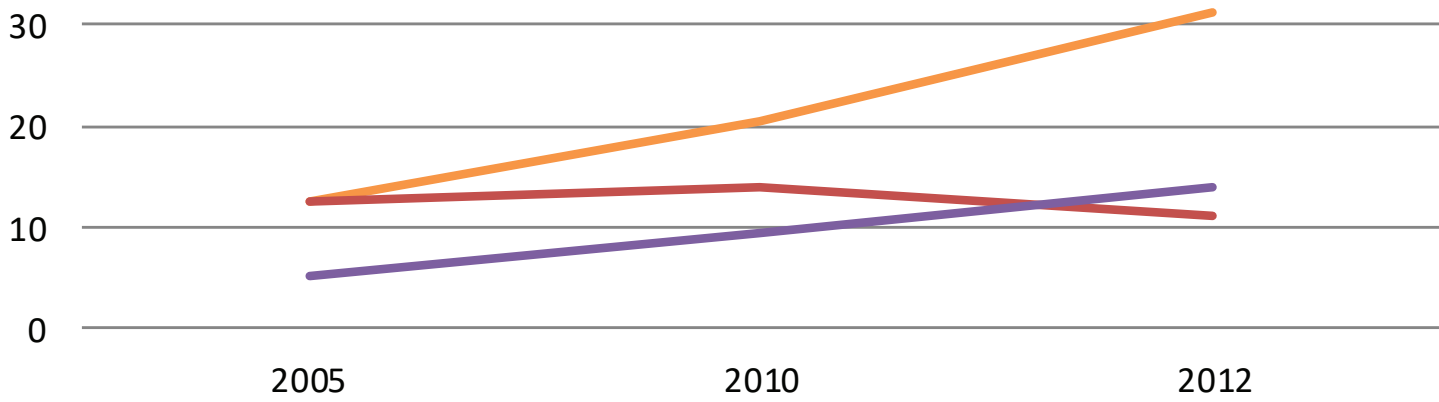

Más bien positivo — Más bien negativo — Ni positivo ni negativo — N.S.

Fuente: CIS, Barómetros autonómicos I, II y III 
En 2012, como refleja el gráfico 13, el 42,7\% de los gallegos ubicaba el Estado de las Autonomías en posiciones centrales en la escala centro-periferia, pero solo el $34,6 \%$ se mostraba partidario de mantener el nivel de autonomía. El 18,9\% prefería una mayor centralización, frente a un $15,5 \%$ de defensores de un Estado más descentralizado. Cabe destacar el alto número de entrevistados ( 3 de cada 10) que en 2012 declaró no saber ubicar el Estado de las Autonomías en esta escala y no tener una preferencia clara sobre el asunto.

\section{Gráfico 13. Percepción de la posición actual del Estado de las Autonomías y preferencias de los gallegos en 2012}

\section{Percepción del modelo actual $\quad$ Preferencia}
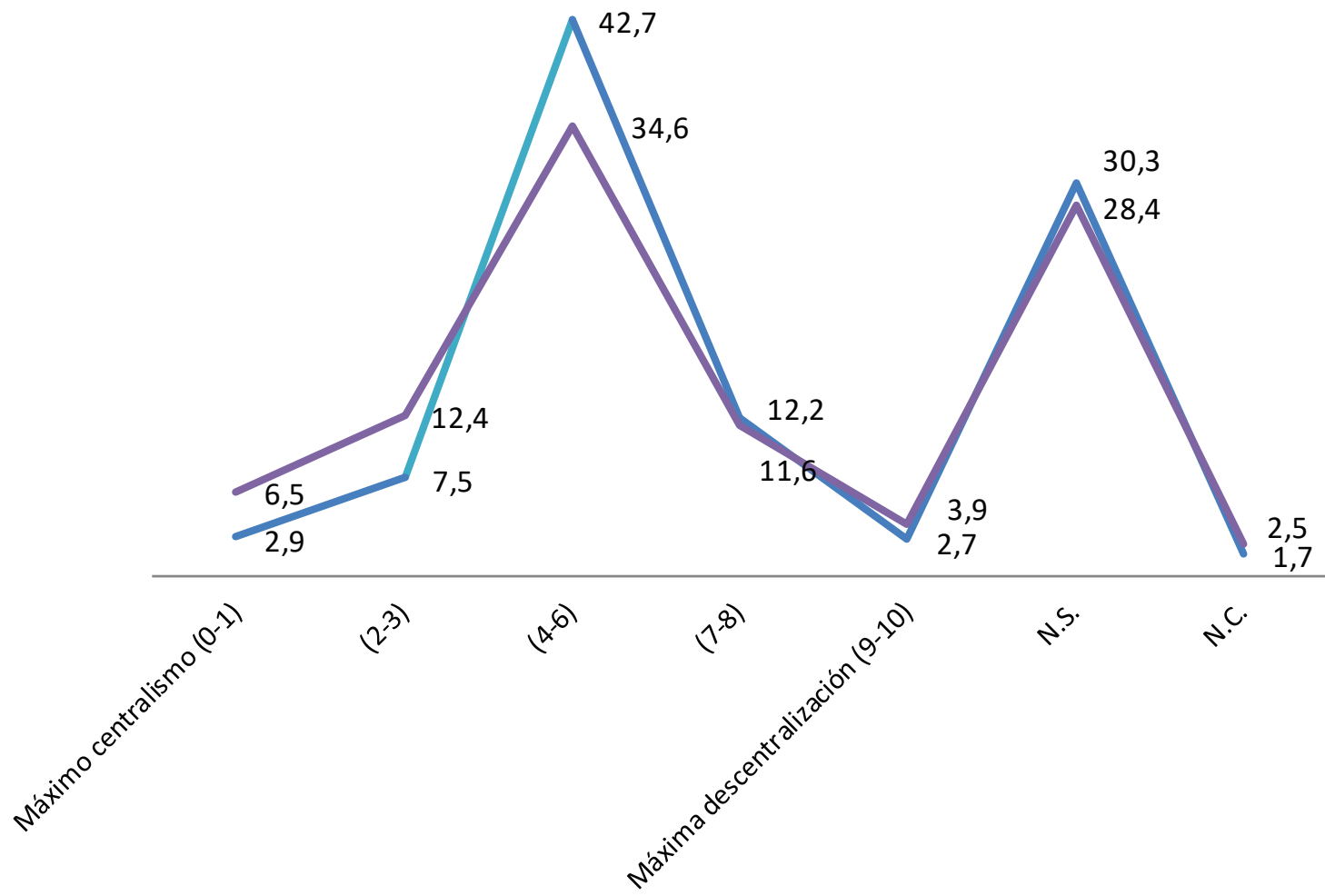

Fuente: CIS, Barómetro autonómico III

El gráfico 14 muestra también el descenso en Galicia del apoyo a los actuales niveles de descentralización, así como el aumento de quienes, en lugar de aumentarla, reducirían la autonomía de las Comunidades. Los partidarios de recentralizar competencias pasaron del 6,6\% de 2005 al 31,5\% en 2012. De hecho, entre 2005 y 2010, coincidiendo con el gobierno bipartito entre PSdeG-PSOE y BNG (2005-2009), esta opción de respuesta (menos autogobierno) creció 21 puntos. Cabe subrayar en este gráfico el irrelevante $(2,7 \%)$ apoyo entre el electorado gallego al reconocimiento del derecho a la independencia, idea que en cambio ha ganado presencia en el discurso del BNG.

Finalmente, el gráfico 15 muestra la evolución de las preferencias de los votantes gallegos sobre la reforma del Estatuto de Autonomía. En 2005, el 42\% creía que el cambio estatutario era poco o nada necesario, frente al 37,2\% que se mostraba a favor de la reforma. En 2012, habían descendido los contrarios al cambio, pero solo el 9,6\% (en 2005 eran el 22,9\%) deseaban más autogobierno. El 31,5\% de los entrevistados prefería una reforma que redujese competencias autonómicas, opción de respuesta que aumentó 25 puntos (del $6,6 \%$ al 31,5\%) desde 2005. 
REALA. Nueva Época - N. 6, noviembre 2016 - ISSN: 1989-8975 - DOI: 10.24965/reala.v0i6.10387 - [Págs. 55-69]

La oferta electoral del Bloque Nacionalista Galego (BNG) en elecciones autonómicas

Cristina Ares Castro-Conde

Gráfico 14. Evolución de la posición de los gallegos sobre el nivel de autonomía de las Comunidades Autónomas

70

60

50

40

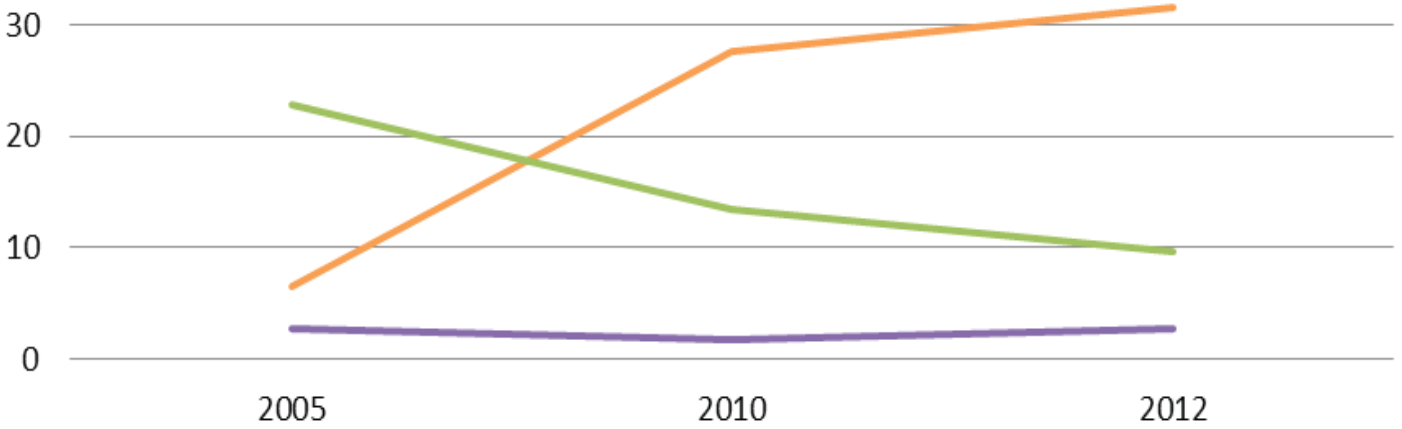

Menor —Igual $—$ Mayor _ Reconocimiento del derecho a la independencia

Fuente: CIS, Barómetros autonómicos I, II y III

Gráfico 15. Valoración en Galicia de la necesidad de reformar el Estatuto de Autonomía

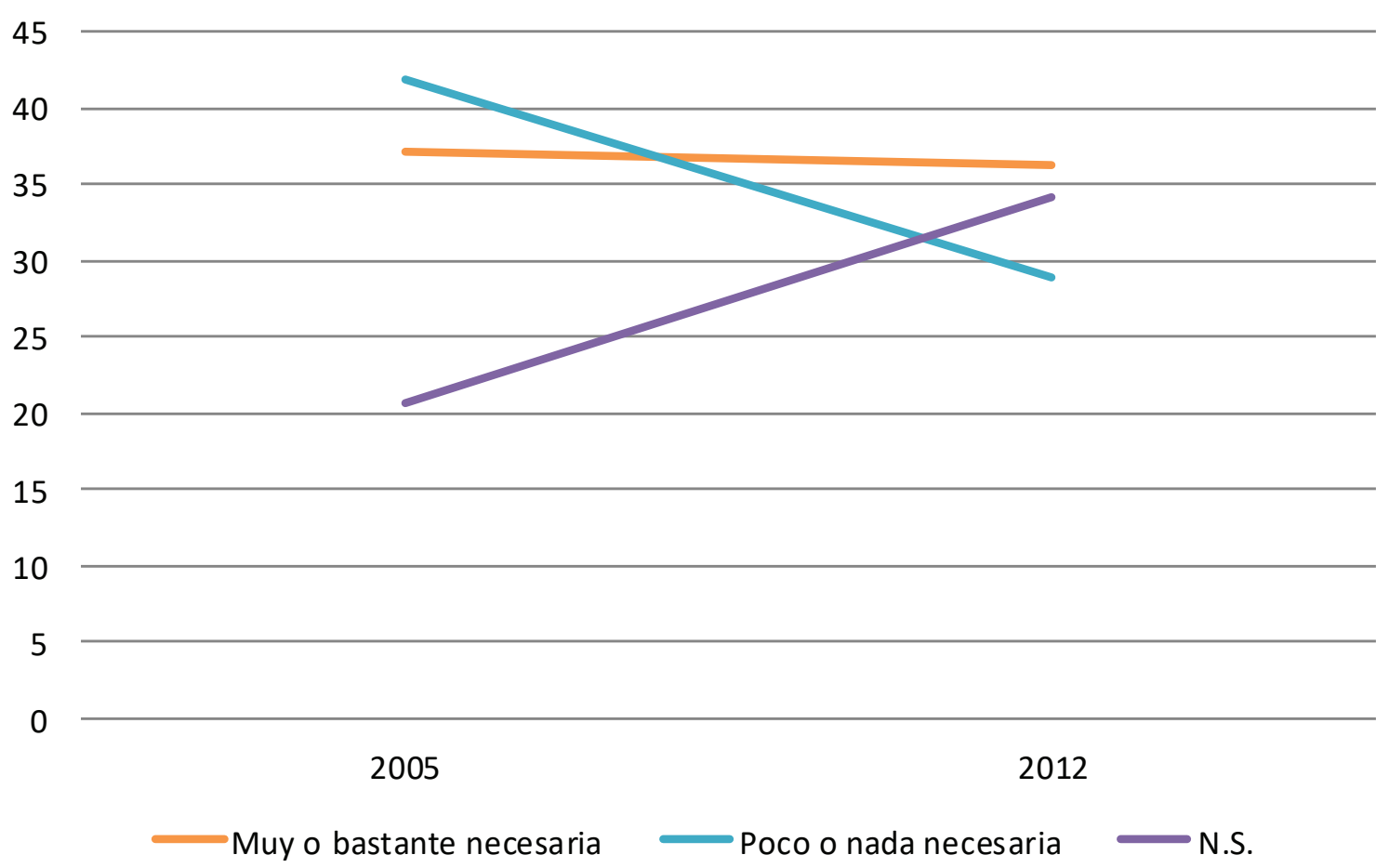

Fuente: CIS, Barómetros autonómicos I y III 


\section{CONCLUSIONES}

En este trabajo se ha abordado el análisis de un resultado político contra-intuitivo en relación con la conformación de gobiernos autonómicos en Cataluña y el País Vasco: el hecho de que un partido nacionalista no haya liderado el Ejecutivo gallego y solo haya accedido a éste en dos ocasiones como socio minoritario de un gobierno de coalición presidido por un socialista.

EI BNG, fuerza que concentró el voto nacionalista entre 1993 y 2012, llegó a superar al PSdeG-PSOE en votos y escaños en 1997, gracias, entre otros factores, a la renuncia a su estrategia de enmarcamiento inicial basada en la confrontación entre «nacionalismo y españolismo» en favor de un nuevo marco integrador de «proyecto común». Sin embargo, desde 2005, su estrategia volvió a mudar. En el eje centro-periferia, el frente incorporó la defensa del reconocimiento a las Comunidades Autónomas de la posibilidad de convertirse en Estados independientes, idea que en Galicia tiene un apoyo de menos del 3\% del electorado; y, en la dimensión izquierda-derecha, abandonó las preferencias centristas sobre las que en 2009 había convergido con el PSdeG-PSOE.

A partir de 2005, la brecha entre el BNG y los electores no ha dejado de crecer, no solo por estos cambios en la estrategia de competición del frente, sino también porque los votantes se han desplazado en el eje territorial en dirección contraria. AGE, en 2012, y En Marea, en 2016, modificaron el escenario de competición en Galicia, favoreciendo el alejamiento del BNG del electorado gallego. En 2020, se observará la voluntad de la nueva dirección frentista para replantear su estrategia en el sentido de aproximarla a las preferencias de los votantes.

\section{BIBLIOGRAFÍA}

ALONSO, S. (2012): Challenging the State: Devolution and the Challenge of Partisan Credibility. Oxford: Oxford University Press.

ALONSO, S. y B. GÓMEZ (2011): «Partidos nacionales en elecciones regionales: ¿coherencia territorial o programas a la carta?», Revista de Estudios Políticos, 152,183-209.

ALONSO, S., A. VOLKENS y B. GÓMEZ (2012): Análisis de contenido de textos políticos. Un enfoque cuantitativo. Madrid: CIS (Colección Cuadernos Metodológicos, 47).

ALONSO, S., B. GÓMEZ y L. CABEZA (2013): «Measuring Centre-Periphery Preferences: The Regional Manifestos Project», Regional \& Federal Studies, 23 (2), 189-211. DOI: 10.1080/13597566.2012.754351.

ALONSO, S., L. CABEZA y B. GÓMEZ (2013): «Manipulating Electoral Externalities in Multi-Level Systems: The Case of PSOE and PP in Spain», ECPR General Conference, Burdeos, 04-07/09/2013.

BARREIRO RIVAS, X. L. (2003): «Da UPG ao BNG: o proceso organizativo do nacionalismo Galego». En J. M. Rivera Otero et al. Os partidos políticos en Galicia, 99-261. Vigo: Xerais.

DE WINTER, L., M. GÓMEZ-REINO y P. LYNCH (2006): «Introduction: Autonomist Parties in European Politics». En: L. De Winter, M. Gómez-Reino y P. Lynch (eds) Autonomist Parties in Europe: Identity Politics and the Revival of the Territorial Cleavage, 13-30. Barcelona: Institut de Ciències Polítiques i Socials.

FERNÁNDEZ BAZ, M. A. (2003): A formación do nacionalismo galego contemporáneo (1963-1984). Noia: Edicións Laiovento.

GÓMEZ B. y L. CABEZA (2013): «Spain: The Persistence of Territorial Cleavages and Centralism of the Popular Party». En: Dandoy, R., y A. H. Schakel (eds): Regional and National Elections in Western Europe. Territoriality of the Vote in Thirteen Countries, 196-215. Nueva York: Palgrave.

GÓMEZ, B. y S. ALONSO (2014): «Los partidos estatales ante el laberinto autonómico». En: F. Pallarés (ed.) Elecciones autonómicas 2009-2012, 75-113. Madrid: CIS.

GÓMEZ-REINO, M. (2006): «The Bloque Nacionalista Galego: from Political Outcast to Success». En: L. De Winter, M. Gómez-Reino y P. Lynch (eds) Autonomist Parties in Europe: Identity Politics and the Revival of the Territorial Cleavage, 167-196. Barcelona: Institut de Ciències Polítiques i Socials.

- (2009): «El nacionalismo minoritario, de la marginalidad al gobierno: la trayectoria del Bloque Nacionalista Galego (1982-2007)», Papers, 92: 119-142.

HEPBURN, E. y K. DETTERBECK (2013): «Federalism, regionalism and the dynamics of party politics». En: J. Loughlin, J. Kincaid, J. y W. Swenden (eds) Routledge Handbook of Regionalism and Federalism, 76-92. Nueva York: Routledge.

JIMÉNEZ, F. (2003): «O PSdeG-PSOE (1973-2001). Un caso de débil institucionalización». En J. M. Rivera Otero et al. Os partidos políticos en Galicia, 265-344. Vigo: Xerais.

JOLLY, S. K. (2015): The European Union and the Rise of Regionalist Parties. University of Michigan Press.

LAGARES, N. (1999): Génesis y desarrollo del Partido Popular de Galicia. Madrid: Tecnos. 
REALA. Nueva Época - N. 6, noviembre 2016 - ISSN: 1989-8975 - DOI: 10.24965/reala.v0i6.10387 - [Págs. 55-69]

La oferta electoral del Bloque Nacionalista Galego (BNG) en elecciones autonómicas

Cristina Ares Castro-Conde

LEÓN, S. (2014): «How does decentralization affect electoral competition of state-wide parties? Evidence from Spain», Party Politics, 20 (3): 391-402.

LIBBRECHT, L., B. MADDENS, W. SWENDEN y E. FABRE (2011): «Issue salience in regional party manifestos in Spain», European Journal of Political Research, 48: 58-79.

LIBBRECHT, L., B. MADDENS y W. SWENDEN (2011): "Party competition in regional elections: The strategies of state-wide parties in Spain and the United Kingdom», Party Politics, 19 (4): 624-640.

MADDENS, B. y L. LIBBRECHT (2009): «How Statewide Parties Cope with the Regionalist Issue: the Case of Spain: A Directional Approach». En: W. Swenden y B. Maddens (eds) Territorial Party Politics in Western Europe, 204-228. Nueva York: Palgrave Macmillan.

MÁIZ, R. (1996): «Nación de Breogán: oportunidades políticas y estrategias enmarcadoras en el movimiento nacionalista gallego» (1886-1996), Revista de Estudios Políticos, 92: 33-75.

- (2001): «El nacionalismo gallego en el s. XX», Ideologías y movimientos políticos, 285-314.

_ (2003): «Making Opportunities», Studies in Ethnicity and Nationalism, 3 (2): 20-34.

MÁIZ, R. y A. LOSADA (2000): «Institutions, Policies and Nation Building: the Galician Case», Regional and Federal Studies, 10 (1): 62-91. DOI: 10.1080/13597560008421109.

PALLARÉS, F. (ed.) (2014): Elecciones autonómicas 2009-2012. Madrid: CIS.

RIVERA, J. M. et al (1998): «Las elecciones autonómicas en Galicia». En M. Alcántara, M. y A. Martínez (ed.) Las elecciones autonómicas en España, 1980-1997, 285-307. Madrid: CIS. 